\title{
Disaccommodation of Magnetic Spectra of Two Manganese Zinc Ferrites
}

\author{
A. L. Rasmussen
}

(October 19, 1964)

\begin{abstract}
Disaccommodation of the complex susceptibility (time change after demagnetization) of two manganese zinc ferrite materials of the composition $\mathrm{Mn}_{0.597} \mathrm{Zn}_{0.265} \mathrm{Fe}_{2.07} \mathrm{O}_{4}$ and $\mathrm{Mn}_{0.584}$ $\mathrm{Zn}_{0.353} \mathrm{Fe}_{2.05} \mathrm{O}_{4}$ was studied in response to demagnetizing frequency and rate, temperature, frequencies of $\sim 20 \mathrm{kHz}$ to $\sim 2000 \mathrm{kHz}$, and rf magnetic field intensities of $\sim 10^{-4}$ oersted and $\sim 10^{-2}$ oersted. Precise susceptibility spectra near $-10.0{ }^{\circ} \mathrm{C}$ show that the resonance maxima shift to higher frequency and decrease in magnitude with increasing time after demagnetization and that the disaccommodation rate varies considerably and changes sign with frequency. Activation energies of the order of 0.8 electron volt were computed at $100 \mathrm{kHz}$.
\end{abstract}

\section{Definitions by Symbols}

$f, \omega=$ Frequency, angular frequency.

$\kappa^{\prime}=$ Real component of relative permittivity.

$\kappa^{\prime \prime}=$ Imaginary component of relative permittivity.

$\chi^{\prime}=$ Real component of the relative susceptibility.

$\chi^{\prime \prime}=$ Imaginary component of the relative susceptibility.

$\chi_{\max }^{\prime}=$ Maximum of the real component of the relative susceptibility.

$f_{\chi_{\max }^{\prime}} \omega_{\chi_{\max }^{\prime}}=$ Frequency, angular frequency corresponding to $\chi_{\max }^{\prime}$.

$\chi_{\mathrm{LF} \text { min }}^{\prime}=$ Low frequency minimum of the real component of the relative susceptibility.

$\chi(t)=\chi^{\prime}$ at a time, $t$, after demagnetization.

$\chi_{0}=\chi^{\prime}$ at time $=0$ after demagnetization.

$\chi_{\infty}=\chi^{\prime}$ at time $=\infty$ after demagnetization.

$E=$ Activation energy.

$\kappa=$ Boltzmann constant.

$T=$ Temperature, degrees Kelvin.

$E_{1}=$ Activation energy corresponding to $\tau_{1}$ values.

$E_{2}=$ Activation energy corresponding to $\tau_{2}$ values.

$E_{0}=$ Mean of $E_{1}$ and $E_{2}$.

\section{Introduction}

Disaccommodation [1] is defined as time change of the magnetic susceptibility after demagnetization. It is described as a wall phenomenon in which the domain walls move less freely in narrowing potential wells. The referenced literature yields information concerning disaccommodation at low and very low frequencies. Nowhere does it describe disaccom- modation through the susceptibility resonance spectra. Disaccommodation of the imaginary component of susceptibility is also not mentioned, probably because the losses were small at the frequencies measured. This paper attempts to partially fill these gaps.

The literature [2-8] shows that the intensity of disaccommodation of ferrite materials in the temperature range of -200 to $+400{ }^{\circ} \mathrm{C}$ and the order of $100 \mathrm{kHz}$ varies considerably with temperature and can be classified into intensity bands which have been attributed to various diffusion and migration processes [1, 9-15] operating upon domain walls. In a given band, the disaccommodation curve, the reciprocal of the susceptibility versus time, may be represented by an equation with a logarithmic distribution of time constants $[11,16]$.

Most disaccommodation measurements in this work were made near $-10.0^{\circ} \mathrm{C}$. At these temperatures and $100 \mathrm{kHz}$ the materials exhibited large disaccommodation and curves approximating a logarithmic distribution of time constants. Figures 1 and 2 illustrate the wide variation of disaccommodation with temperature. Lower temperatures were not available with the equipment used. Time constants and activation energies were calculated using data from these figures.

Disaccommodation as determined from the complex susceptibility of two manganese zinc ferrite materials was studied in response to demagnetizing frequency and rate, temperature, frequencies of $\sim 20 \mathrm{kHz}$ to $\sim 2000 \mathrm{kHz}$, and rf magnetic field intensities of $\sim 10^{-4}$ oersted and $\sim 10^{-2}$ oersted.

Precise susceptibility spectra near $-10.0{ }^{\circ} \mathrm{C}$ show that the resonance maxima shift to higher frequency and decrease in magnitude with increasing time after demagnetizing and that the disaccommodation rate varies considerably and changes sign with frequency. Activation energies of the order of 0.8 electron volt were computed at $100 \mathrm{kHz}$. 


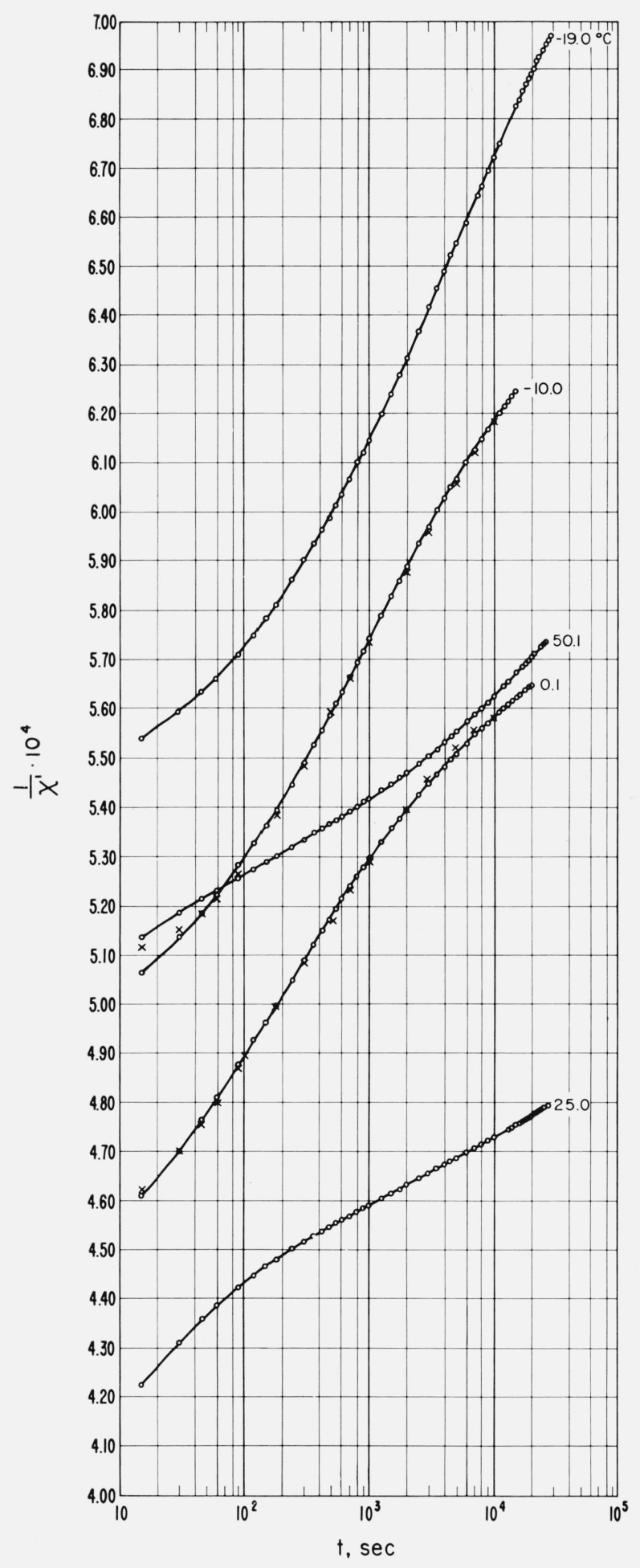

Figure 1. Material A. $100 \mathrm{kHz}$ disaccommodation data at various temperatures, $1 / \chi^{\prime}$ versus time after the completion of $20 \mathrm{kHz}$ a-c field demagnetization.

$H_{\mathrm{rf}}=8.4 \times 10^{-5}$ oersted. The points marked with $x$ 's are calculated values using

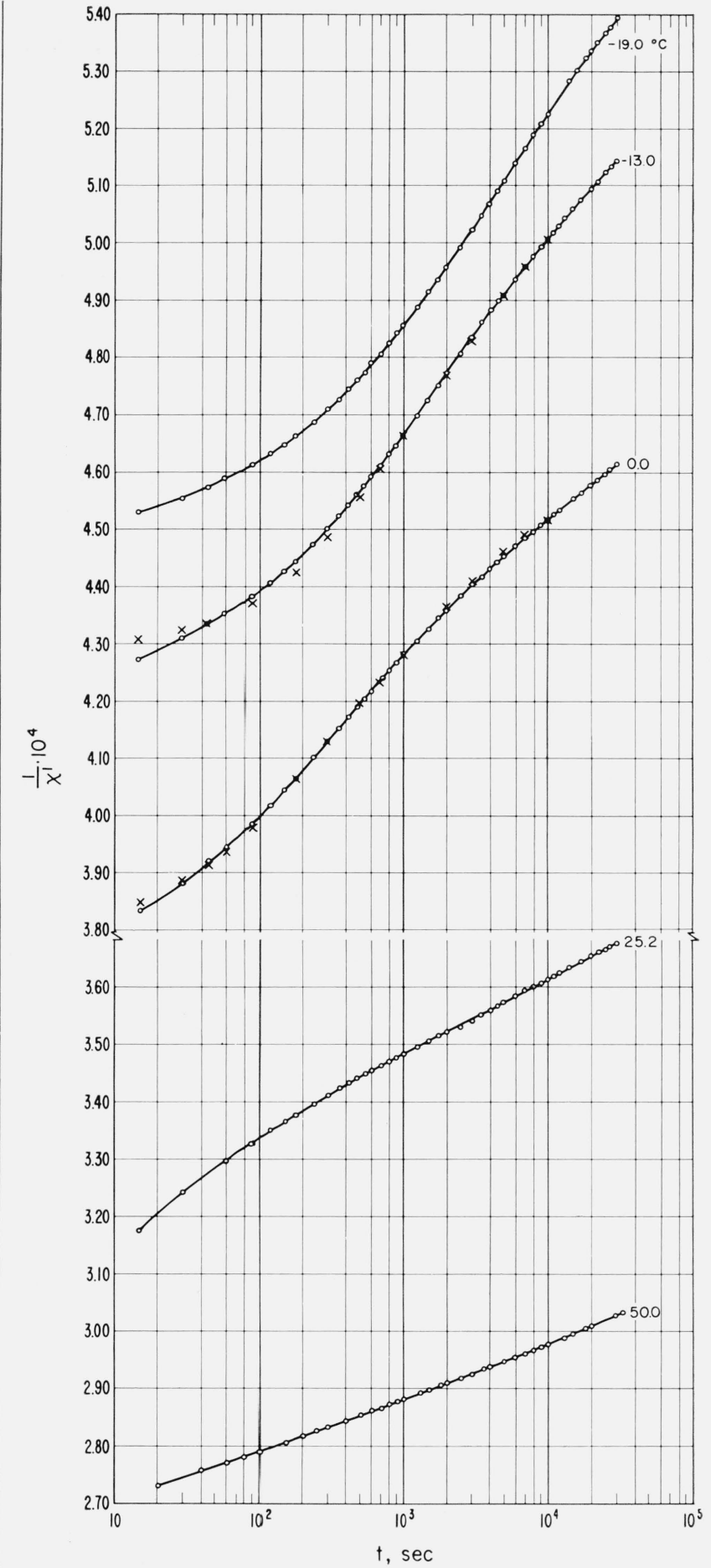

Figure 2. Material B. $100 \mathrm{kHz}$ disaccommodation data at various temperatures, $1 / \chi^{\prime}$ versus time after the completion of $20 \mathrm{kHz} a-c$ field demagnetization.

$H_{\mathrm{rf}}=8.5 \times 10^{-5}$ oersted. The points marked with $x$ 's are calculated values using eq (4) of section 5 . 


\section{Materials}

The materials were commercial manganese zinc composition, chosen for study because of their extreme instability in susceptibility. Their chemical composition is

\begin{tabular}{|c|c|c|}
\hline Material & Composition & Density \\
\hline $\begin{array}{l}\mathrm{A}_{\ldots} \ldots \ldots \\
\mathrm{B}_{\ldots} \ldots \ldots\end{array}$ & $\begin{array}{l}\mathrm{Mn}_{0.597} \mathrm{Zn}_{0.265} \mathrm{Fe}_{2.07} \mathrm{O}_{4 \ldots} \ldots \ldots \\
\mathrm{Mn}_{0.584} \mathrm{Zn}_{0.353} \mathrm{Fe}_{2.05} \mathrm{O}_{4 \ldots} \ldots \ldots \ldots\end{array}$ & $\begin{array}{r}\mathrm{g} / \mathrm{cm}^{3} \\
4.83 \\
4.80\end{array}$ \\
\hline
\end{tabular}

\section{Measurement Techniques}

The following are discussed: temperature equipment, demagnetization procedure, stray and radiofrequency fields, measurement details, precision and accuracy, and permittivity and resistivity of the materials.

The temperature equipment, figure 3 , was designed to avoid mechanically shocking the sample and to maintain temperatures within $\pm 0.10{ }^{\circ} \mathrm{C}$. These precautions were necessary to obtain precise data. An antifreeze solution was pumped at the desired temperature through the brass tubing coil inside the Dewar. Temperature was monitored by a thermoelement near the sample and adjusted by a thermostat in the antifreeze bath. Fiberglass insulation was supplied where needed. A drying agent was used in the Dewar.

EQUIPMENT FOR DISACCOMMODATION MEASUREMENT

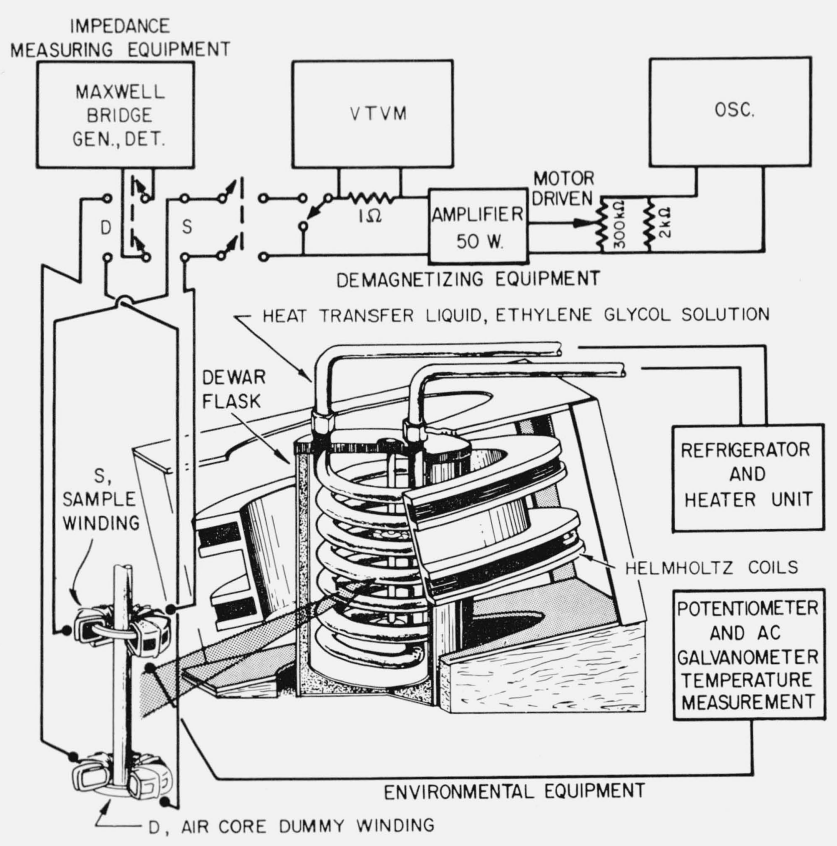

Figure 3. Diagram of equipment used in obtaining experimental data.

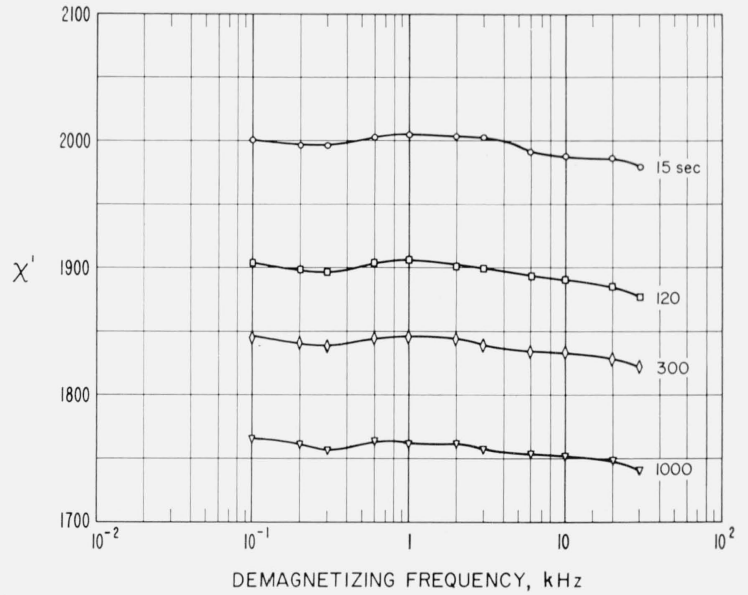

Figure 4. Material A. $100 \mathrm{kHz}$ susceptibility versus demagnetizing frequency at given times after the completion of $a-c$ field demagnetization.

$$
H_{\mathrm{rf}}=8.4 \times 10^{-5} \text { oersted. Temperature }=-10.0^{\circ} \mathrm{C} .
$$

Since disaccommodation varies considerably with temperature, thermal demagnetization was considered impractical in this work. A-c field demagnetization in the direction of the applied rf field and of the circumference of the toroidal specimen was used [17]. A demagnetizing field of $20 \mathrm{kHz}$ was applied decreasing uniformly from $\sim 10$ oersteds to $\sim 10^{-4}$ oersted in 0.28 second. The sample winding was switched to a rf bridge immediately afterwards. Figure 4 shows the susceptibility is a slowly varying function of the demagnetizing frequency. Increasing the demagnetizing time 2 and 3 times 0.28 second yields the same curves. The demagnetizing field did not overheat the sample; and, in the region near $-10{ }^{\circ} \mathrm{C}$, it yielded to a close approximation the same susceptibility-time curve for increments of the order of \pm 33 percent in its initial value. With increments larger than +33 percent, the temperature of the sample rose because of the power dissipated in the demagnetizing winding. The susceptibility was thus changed. If the field is decreased more than 33 percent, lower susceptibility values resulted, presumably because the sample was not completely demagnetized.

The stray field was reduced to $\sim 10^{-2}$ oersted in the vicinity of the sample by using helmholtz coils, figure 3. This prevented partial magnetization of the sample. Subsequent measurements indicated this special precaution unnecessary. Values of $\mathrm{rf}$ magnetic field were $\sim 10^{-4}$ oersted for all measurements except for one disaccommodation magnetic spectra of material A where fields $\sim 10^{-2}$ oersted were used. Here a low pass filter was attached to the rf bridge generator at each frequency to prevent the sample from exhibiting an impedance at harmonics of the generator. Disaccommodation data at any given frequency were not affected by connecting or disconnecting the sample winding from the rf bridge or making disaccommodation measurements at other frequencies in the interim. 
Impedance measurements, figure 3, of wound forms with and without the sample were made using a high precision, hf Maxwell impedance bridge at very low power levels. The sample and dummy windings were made as nearly alike as possible and had a low capacity. The winding to measure the impedance was also used to demagnetize the sample. The susceptibility was calculated [18] as follows:

$$
\begin{gathered}
\chi^{\prime}-j \chi^{\prime \prime}=\frac{L_{\text {sample }}-L_{\text {dummy }}}{\left(N_{\text {turns }}\right)^{2} L_{\text {air inductance of sample }}} \\
-j \frac{R_{\text {sample }}-R_{\text {dummy }}}{\omega\left(N_{\text {turns }}\right)^{2} L_{\text {air inductance of sample }}} .
\end{gathered}
$$

In summary, to measure the sample the following procedure was used:

(1) The wound sample and the wound dummy were allowed to reach thermal equilibrium in a Dewar at the desired temperature.

(2) The field in the sample was adjusted to the desired value.

(3) The impedance of the dummy winding was measured using the bridge.

(4) The sample was demagnetized at a given frequency, generally $20 \mathrm{kHz}$, in $\sim 0.28$ second except where mentioned otherwise in the text.

(5) The sample winding was switched to the bridge operating at the desired frequency.

(6) The impedance of the sample was measured at the desired times after demagnetization while maintaining all field and temperature conditions.

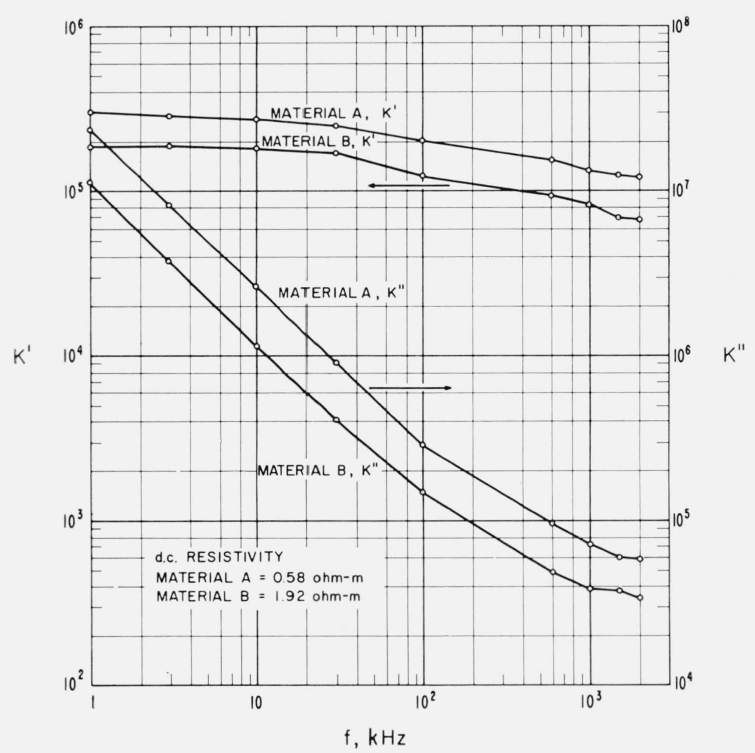

Figure 5. Materials $A$ and $B$. Relative complex permittivity versus frequency and $d-c$ resistivity at ambient temperature of $23{ }^{\circ} \mathrm{C}$.
Repeatability of all impedance data was approximately \pm 0.1 percent except occasionally at the initial portion of the disaccommodation curve it was the order of \pm 0.2 percent. Precision was approximately \pm 0.05 percent to \pm 0.1 percent. The errors of $L$ and $R$ from the winding capacity were evaluated to be $\sim 1$ percent or less at $2000 \mathrm{kHz}$.

In evaluating the susceptibility error, consideration was given to dimensional effects resulting from the high permittivities of the materials [19]. Toroidal samples used to measure susceptibility were OD $2.49 \mathrm{~cm}$, ID $2.24 \mathrm{~cm}$ and height $0.127 \mathrm{~cm}$ yielding a $0.127 \mathrm{~cm} \times 0.127 \mathrm{~cm}$ square cross section. Disk and bar samples used to measure permittivity were (1) $\mathrm{OD} \sim 0.25 \mathrm{~cm}$ and height $\sim 0.25 \mathrm{~cm}$ and (2) length $1.5 \mathrm{~cm}$ and $0.5 \mathrm{~cm} \times 0.5 \mathrm{~cm}$ square cross section, respectively. Two terminal techniques were used to measure the properties of the disk samples, and four terminal techniques to measure the bars at lower frequencies. The two methods yielded comparable results where the data overlappec. The bars were also used to measure d-c resistivity. Data are shown in figure 5. The error in $\chi^{\prime}$ and $\chi^{\prime \prime}$ for the materials at $2000 \mathrm{kHz}$ and $23{ }^{\circ} \mathrm{C}$ was estimated to be the order of 1 and 5 percent, respectively, using equations found in [19]. It is estimated the error is the same order at lower temperatures.

\section{Disaccommodation Spectra Data}

A description is given of disaccommodation spectra data appearing in figures 6 through 13 . The various times appearing in the figures refer to the time lapsed after completion of $20 \mathrm{kHz}$ demagnetization process described in section 3 .

Susceptibility-temperature curves at several times, figures 6 and 7 , show (1) the susceptibility of material $\mathrm{A}$ has a maximum at $25^{\circ} \mathrm{C}$ which decreases with time and (2) the susceptibility of material B, initially linear, develops a curvature with time.

Complex susceptibility frequency spectra at the given times, figures 8 through 10, show (a) the resonance maxima shift to higher frequency, decrease in magnitude and remain left of the retreating high frequency side of the spectra; the resonance peaks broaden considerably with some reduction in magnitude when $H_{\mathrm{r}}$ is increased a hundred times for material A shown in figure 9; and (b) values of the variable, $\Delta \chi^{\prime}=\left(\chi_{\max }^{\prime}-\chi_{L F \min }^{\prime}\right)$, increase with time.

The real susceptibility versus time curves at various frequencies, figure 11 , show that with positive increments of frequency the mean slope gradually decreases, then increases and becomes positive. The imaginary component follows a similar pattern to the region where measurements ceased. The disaccommodation varies considerably over the frequency range, the real component increasing with time at the high frequency end. These variations are observed as changes with time in the susceptibilility frequency spectra. Disaccommodation data are not affected by making disaccommodation measurements at other frequencies in the interim of measurements at a given frequency. 


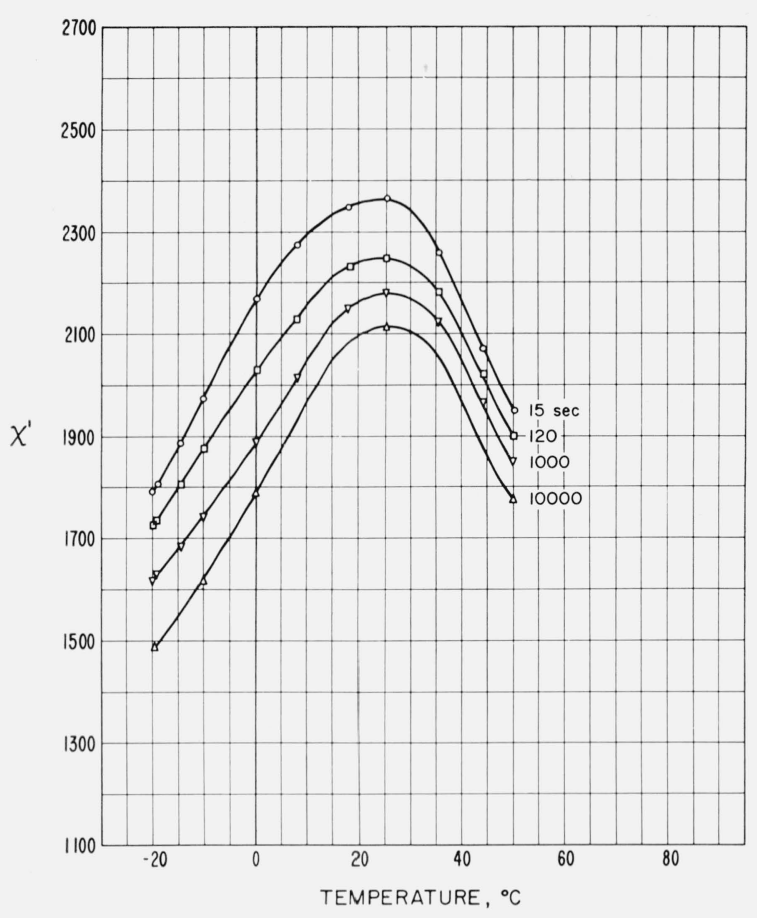

Figure 6. Material A. $100 \mathrm{kHz}$ disaccommodation data, $\chi^{\prime}$ versus temperature at given times after the completion of $20 \mathrm{kHz} a-c$ field demagnetization.

$H_{\mathrm{rf}}=8.4 \times 10^{-5}$ oersted.

The reciprocal of the complex susceptibility or the complex reluctivity, $\chi^{\prime} /\left(\chi^{\prime 2}+\chi^{\prime \prime 2}\right)$ and $\chi^{\prime \prime}$, $\left(\chi^{\prime 2}+\chi^{\prime \prime 2}\right)$, versus time curves at various frequencies, figure 12 for material $\mathrm{A}$, shows that the real component curves have positive slope tending toward zero at higher frequencies and the imaginary component, negative slope. These expressions may be useful in defining disaccommodation for the user of materials.

Disaccommodation of ferrite materials has been attributed to a domain wall related mechanism $[1,9-15,20-22]$. If the resonance found in the susceptibility spectra is predominately from domain wall motion, it was thought that the application of the domain wall equation to the data may help in understanding the disaccommodation mechanism. The spectra of these materials at room temperature show only one resonance to $100 \mathrm{MHz}$. With high zinc content it is possible that the wall resonance frequency and the rotation resonance frequency, if both exist, are close together or coalesce [23-25] Indirect evidence that domain wall motion may contribute a major role to the susceptibility are the low porosity [23], the high susceptibility, the high temperature coefficient of susceptibility [25], the large disaccommodation of the materials [14], the low resonance frequencies $[23,25]$, and the sharpness and magnitude of the resonance. For these reasons, the domain wall motion equation was applied to the experimental data.

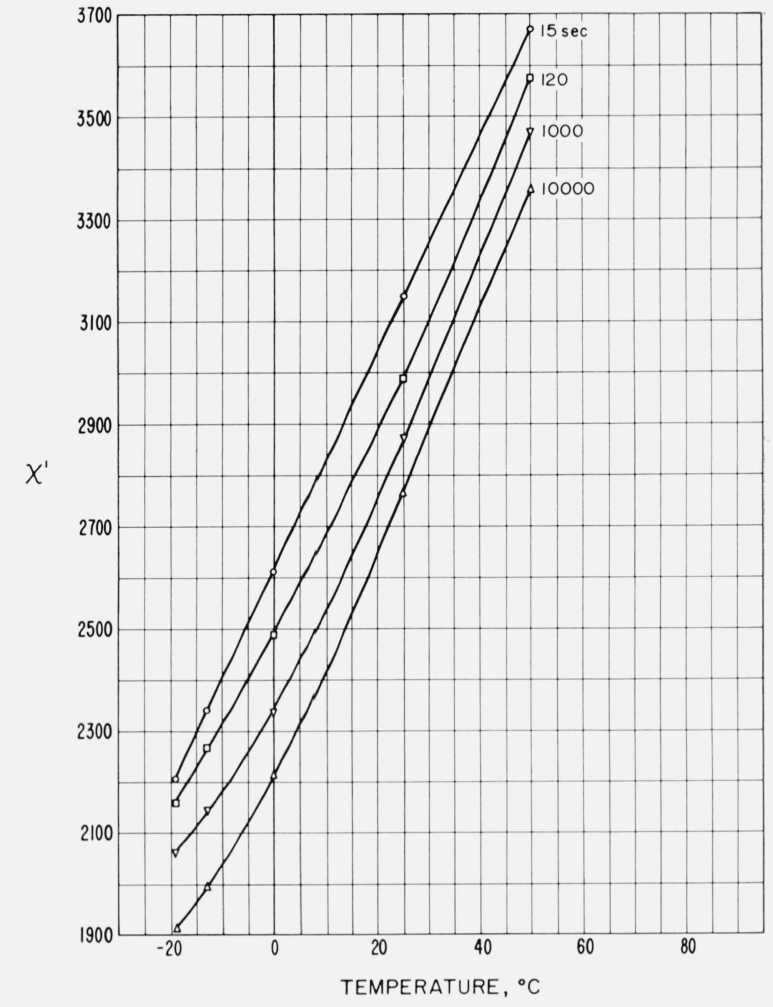

Figure 7. Material B. $100 \mathrm{kHz}$ disaccommodation data, $\chi^{\prime}$ versus temperature at given times after the completion of $20 \mathrm{kHz}$ a-c field demagnetization.

$$
H_{\mathrm{rf}}=8.5 \times 10^{-5} \text { oersted. }
$$

The motion of an average wall under the influence of an alternating field is [23-26]

$$
m \frac{d^{2} x}{d t^{2}}+\beta \frac{d x}{d t}+\alpha x=N M_{s} H_{0} \exp (j \omega t)
$$

where

$x=$ the displacement of the wall from its equilibrium position;

$m=N_{m} / \gamma^{2} \delta=$ wall inertia or apparent mass per unit area of wall;

$\beta=N_{\beta} \lambda / \gamma^{2} \delta=$ opposing force or damping coefficient;

$\alpha=$ restoring force;

$M_{s}=$ saturation magnetization;

$H_{0} \exp (j \omega t)=$ applied field;

$N, N_{m}$ and $N_{\beta}=$ constants depending on the type of domain wall;

$\gamma=$ magneto-mechanical ratio of an electron;

$\lambda=$ relaxation frequency or damping factor from Landau Lifshitz equation of motion;

$\delta=$ Domain wall thickness. 

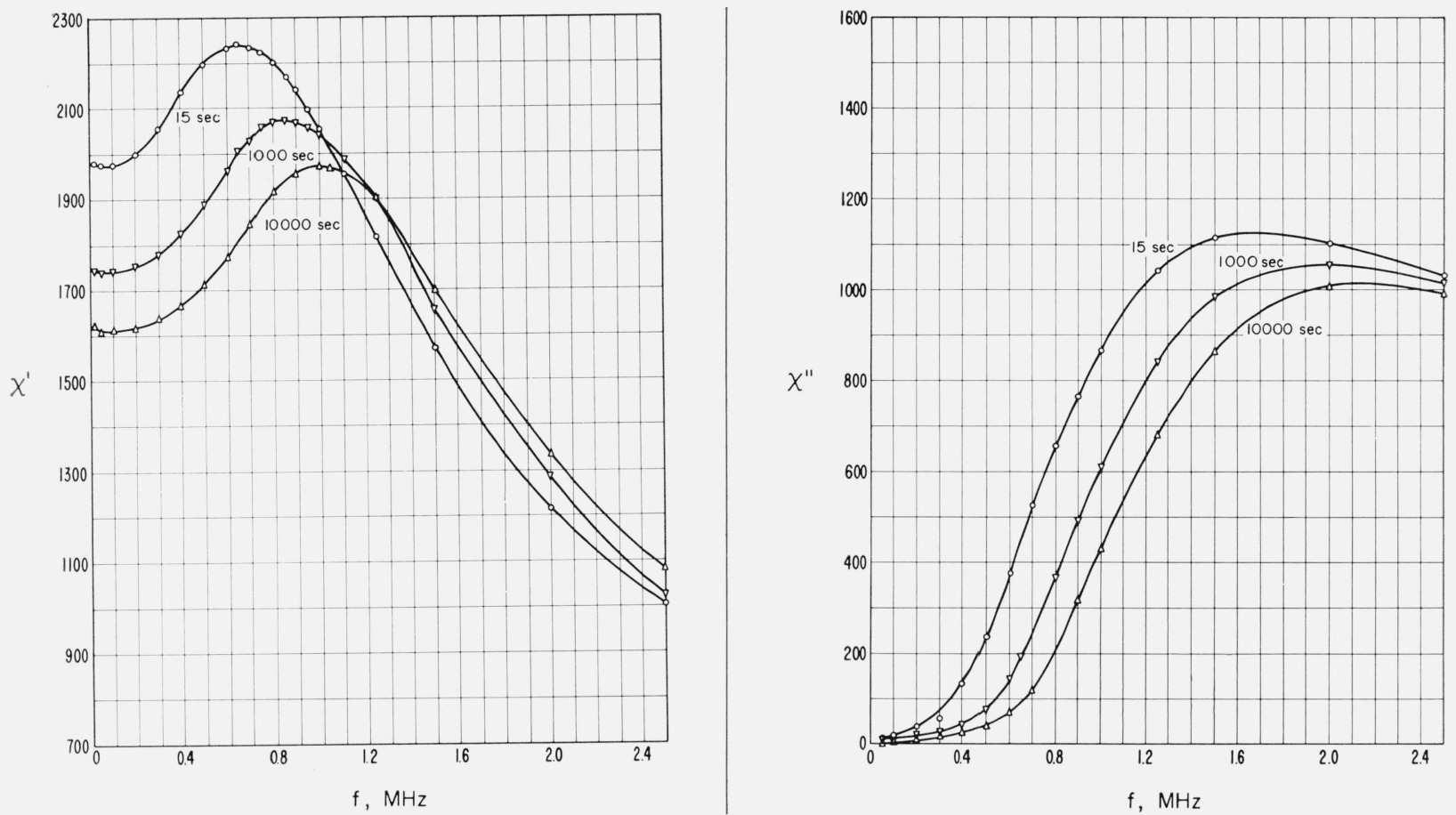

Figure 8. Material A. Disaccommodation, $\chi^{\prime}$ and $\chi^{\prime \prime}$ versus frequency at given times after the completion of $20 \mathrm{kHz} a-c$ field demagnetization.

$H_{\mathrm{r} f}=8.4 \times 10^{-5}$ oersted. Temperature $=-10,0^{\circ} \mathrm{C}$.
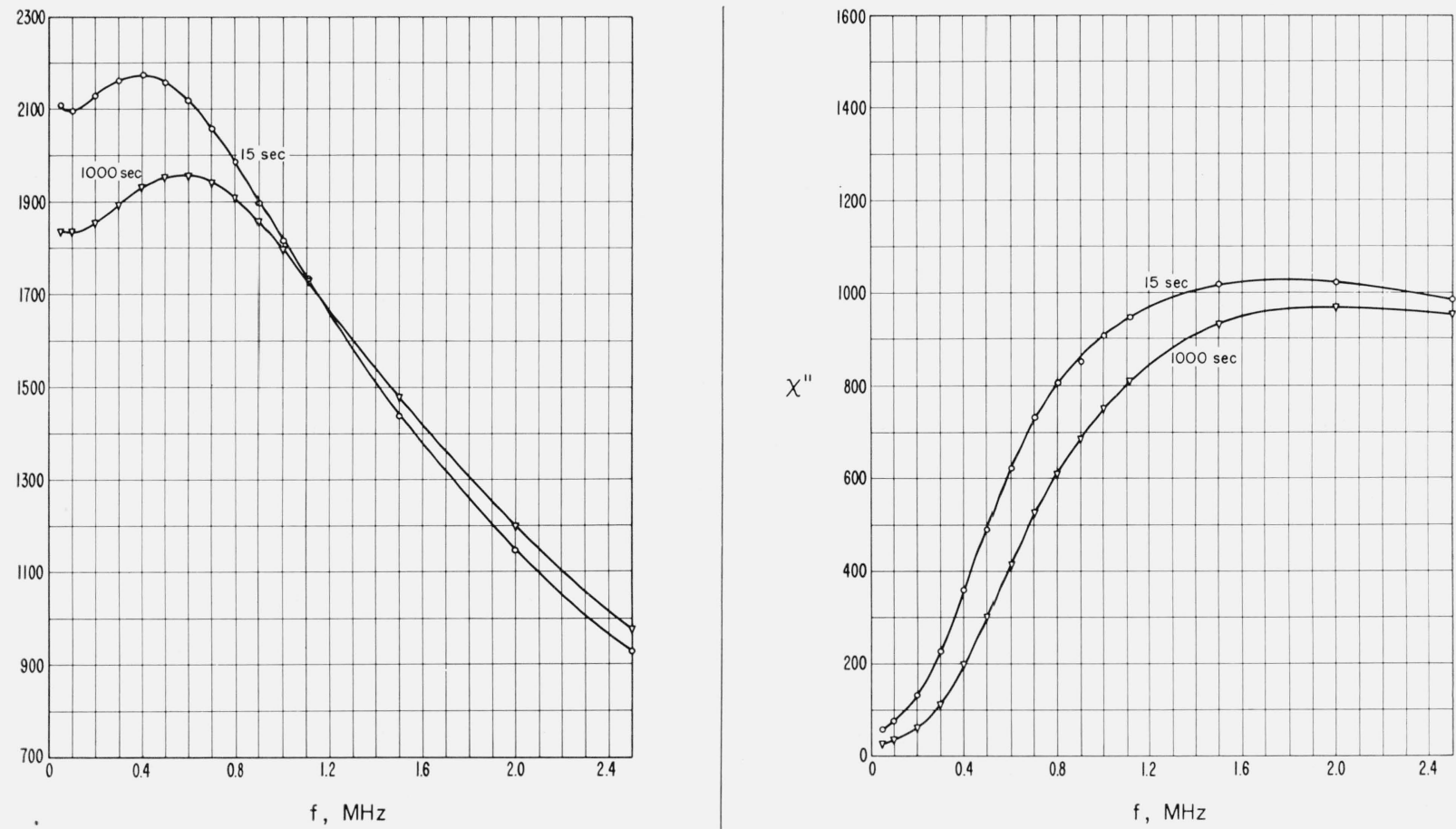

Figure 9. Material A. Disaccommodation, $\chi^{\prime}$ and $\chi^{\prime \prime}$ versus frequency at given times after the completion of $20 \mathrm{kHz}_{\mathrm{a}} \mathrm{c}$ field demagnetization.

$H_{\mathrm{r} \ell}=8.4 \times 10^{-3}$ oersted $(100$ times value of fig. 8$)$. Temperature $=-10.0^{\circ} \mathrm{C}$. 

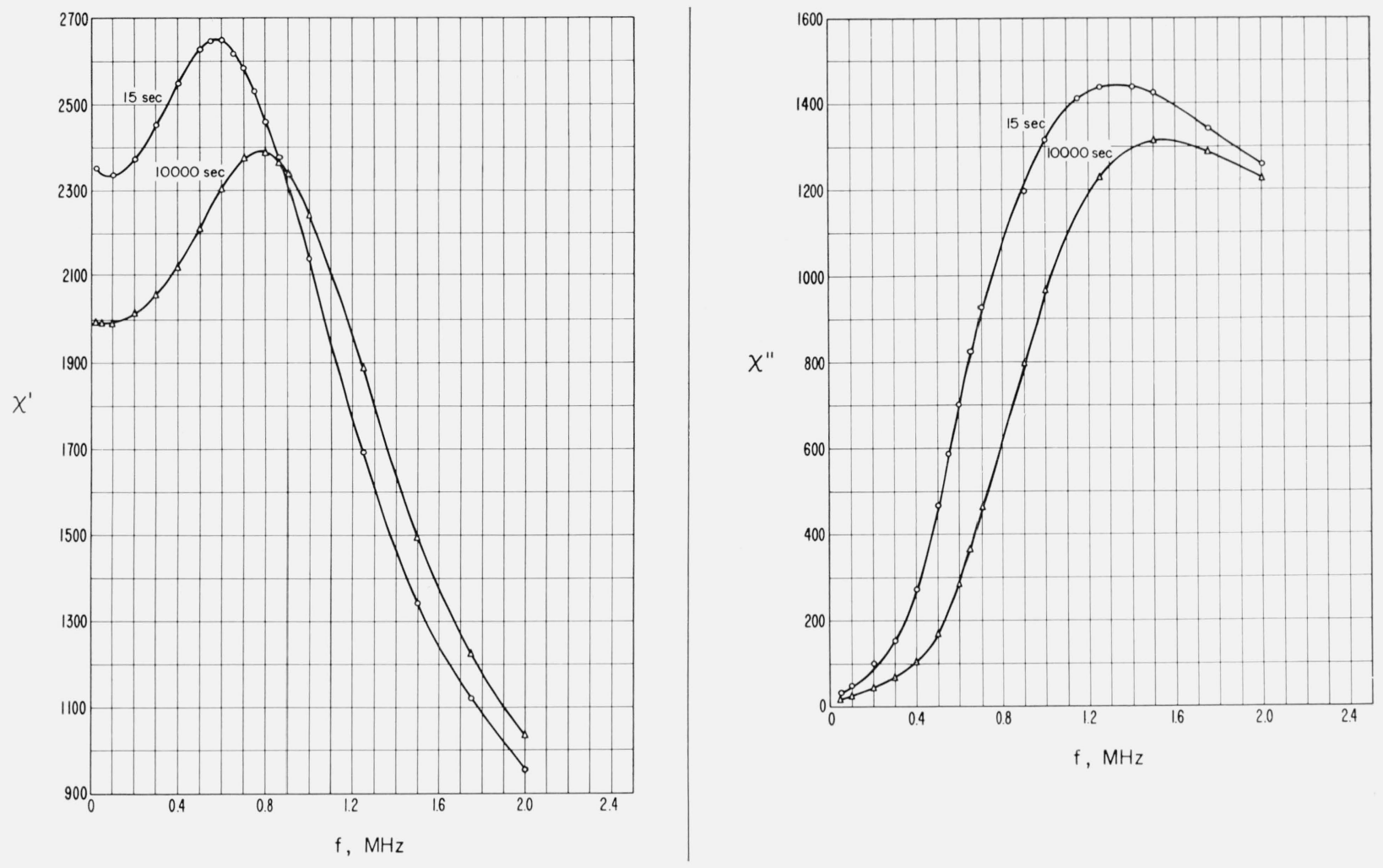

Figure 10. Material B. Disaccommodation, $\chi^{\prime}$ and $\chi^{\prime \prime}$ versus frequency at given times after the completion of $20 \mathrm{kHz}$ a-c field demagnetization.

$H_{\mathrm{rf}}=8.5 \times 10^{-5}$ oersted. Temperature $=-13.0^{\circ} \mathrm{C}$.

It can be shown that [24]

$$
\begin{aligned}
\chi^{\prime}-j \chi^{\prime \prime}=\frac{\left[1-\left(\omega / \omega_{0}\right)^{2}\right]}{\left[1-\left(\omega / \omega_{0}\right)^{2}\right]^{2}+} & \left(\omega / \omega_{c}\right)^{2} \\
& -j \frac{\left(\omega / \omega_{c}\right) \chi_{s}}{\left[1-\left(\omega / \omega_{0}\right)^{2}\right]^{2}+\left(\omega / \omega_{c}\right)^{2}}
\end{aligned}
$$

where

$$
\begin{aligned}
& \omega_{0}^{2}=\alpha / m \\
& \omega_{c}=\alpha / \beta \\
& \chi_{s}=N M_{s}^{2} / \alpha d, \text { relative static susceptibility and } \\
& d=\text { domain thickness. }
\end{aligned}
$$

Application of eq (2) to the data leads to the conclusion that the relaxation frequency, $\lambda$, and the ratio of domain wall thickness to domain thickness, $\delta / d$, are increasing with time. If the anisotropy energy (discussed in the literature in relation to disaccommodation mechanism [13-15, 21, 22, 27-29]) is changing by a sufficiently large amount with time, the domain structure may be affected. However, any conclusions drawn from the wall equation are uncertain because it poorly fits the data. A more quantit ative analysis of the data may require separat- ing domain wall and domain rotation susceptibili ties and using a distribution of $\omega_{0}$ and $\omega_{c}$ values Other data may also be necessary. An explanation remains to be given of the changes with time in the magnetic spectra where the maxima and low frequency minima values of susceptibility are decreasing and the resonant frequencies are increasing after the demagnetization process.

\section{Calculation of Time Constants and Activation Energies}

The susceptibility and time relation for domain wall motion may empirically be expressed as [11, $16,30,31]$

$$
\begin{aligned}
\frac{1}{\chi(t)}=\frac{1}{\chi_{0}}+ & \left(\frac{1}{\chi_{\infty}}-\frac{1}{\chi_{0}}\right) \\
& \left\{1+\frac{1}{\ln \frac{\tau_{2}}{\tau_{1}}}\left[E i\left(-\frac{t}{\tau_{2}}\right)-E i\left(-\frac{t}{\tau_{1}}\right)\right]\right\} .
\end{aligned}
$$

The function in braces is designated $G(t)$ and represents a logarithmic distribution of time constants where $\tau_{1}$ is the shortest and $\tau_{2}$ is the longest time 

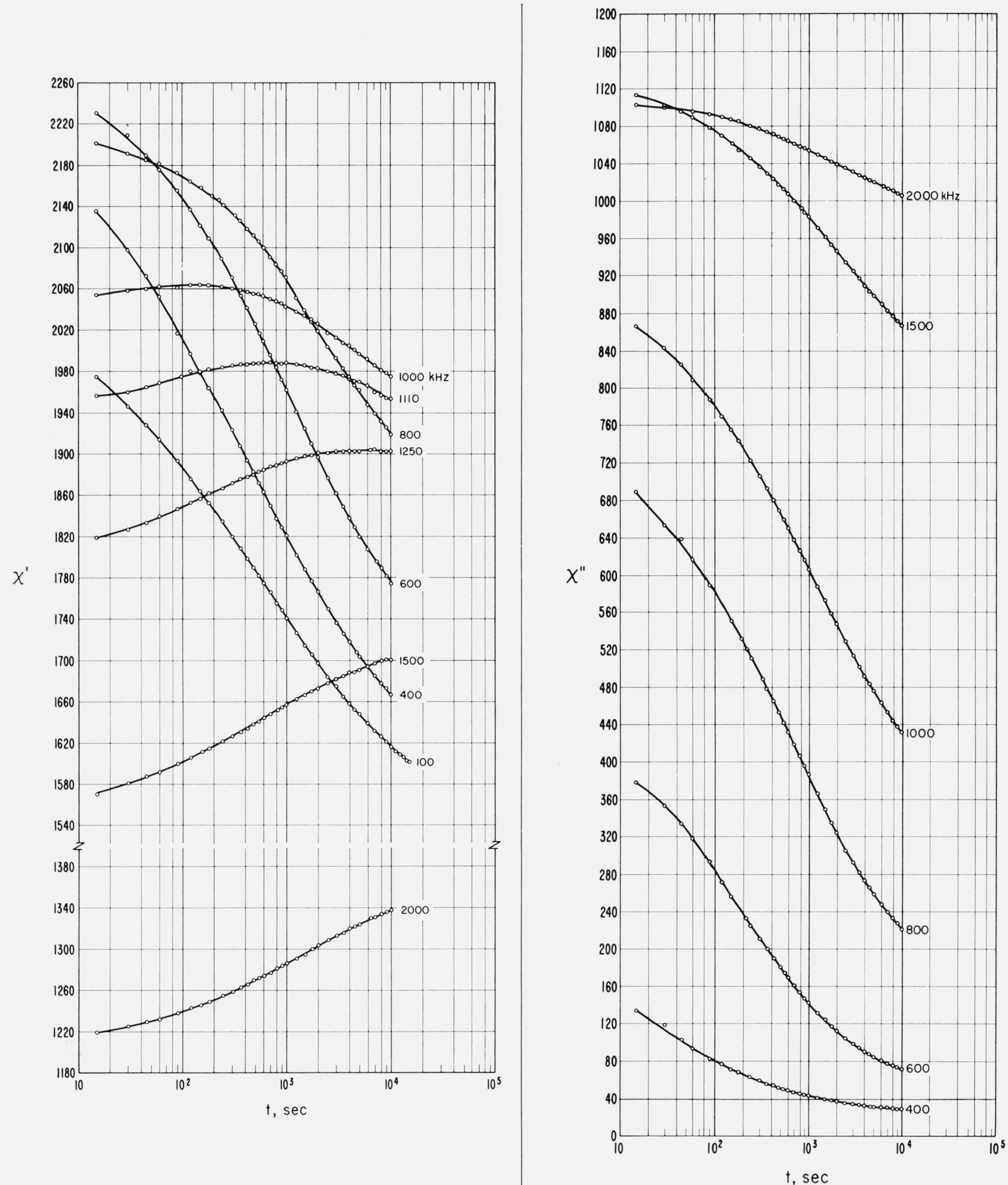

Figure 11. Material A. Disaccommodation data at various frequencies, $\chi^{\prime}$ and $\chi^{\prime \prime}$ versus time after the completion of 20 $\mathrm{kHz}$ a-c field demagnetization.

$H_{\mathrm{r} f}=8.4 \times 10^{-5}$ oersted. Temperature $=-10.0^{\circ} \mathrm{C}$ 

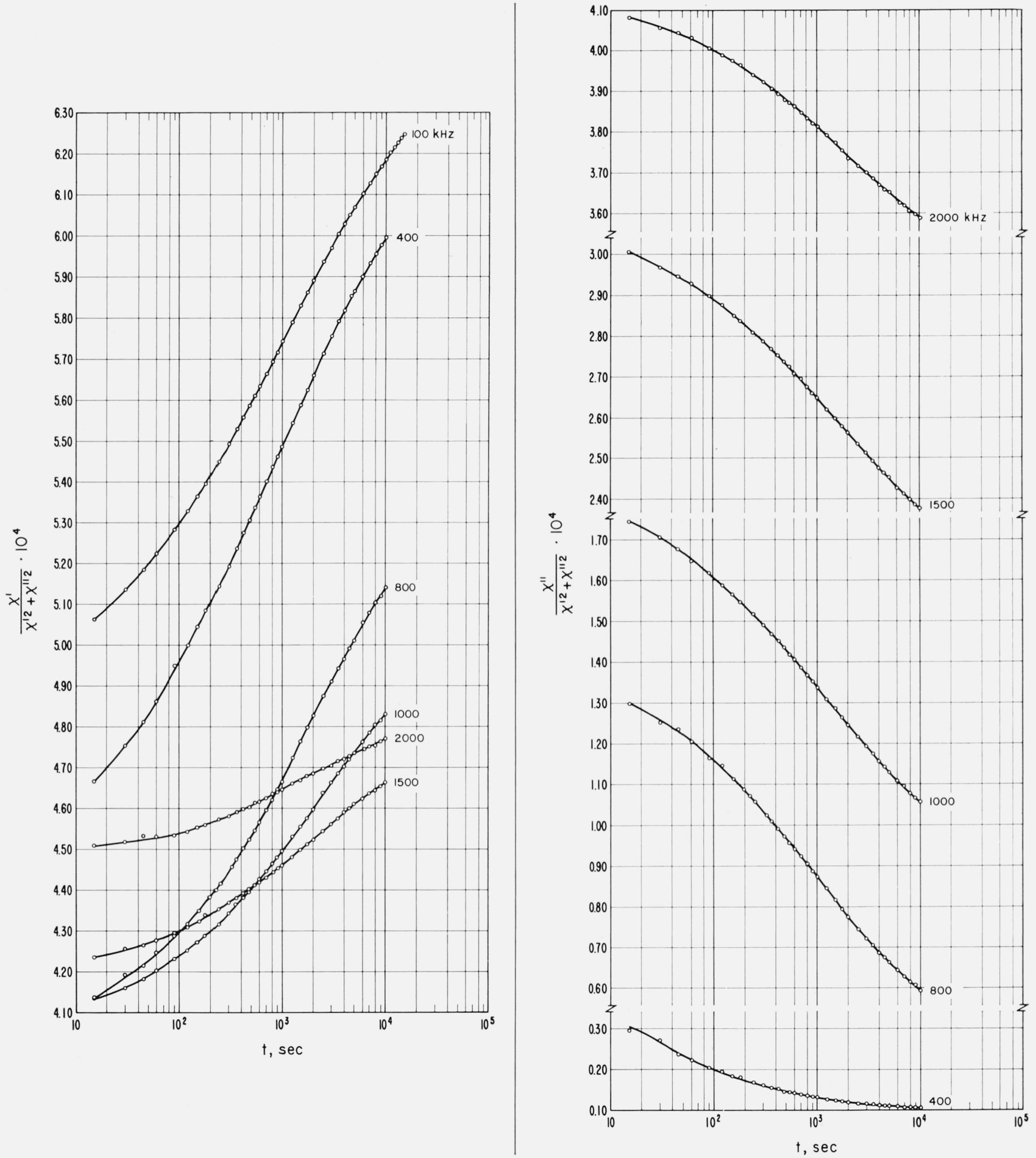

Figure 12. Material A. Disaccommodation data at various frequencies, $\chi^{\prime} /\left(\chi^{\prime 2}+\chi^{\prime \prime 2}\right)$ and $\chi^{\prime \prime} /\left(\chi^{\prime 2}+\chi^{\prime \prime 2}\right)$ versus time after the completion of $20 \mathrm{kHz}$ a-c field demagnetization. $H_{\mathrm{rf}}=8.4 \times 10^{-5}$ oersted. Temperature $=-10.0^{\circ} \mathrm{C}$. 

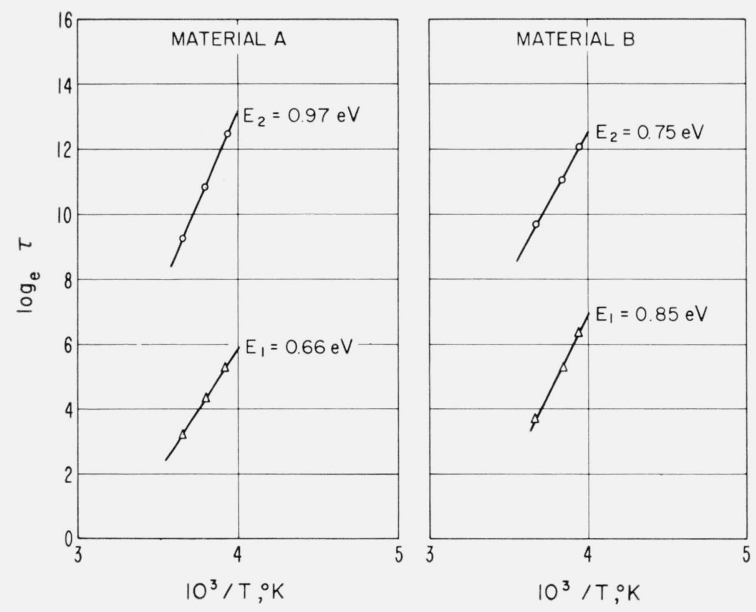

Figure 13. Materials $A$ and $B .100 \mathrm{kHz}$ time constant $(\tau)$ and activation energy $(E)$ daia.

(Equations and more data are described in section 5 and table- 1 of the text.)

constant. $G(t)$ was used by Richter [32], Becker [33], and Néel [31] and may be expressed as

$$
\frac{1}{\ln \tau_{2} / \tau_{1}} \int_{\tau_{1}}^{\tau_{2}}\left(1-e^{-t / \tau}\right) \frac{d \tau}{\tau}
$$

It will be seen that the experimental results fit eq (3) very well.

Equation (3) may be expressed as [11]

$$
\frac{1}{\chi(t)}=\frac{1}{\chi_{\infty}}+B\left[E i\left(-\frac{t}{\tau_{2}}\right)-E i\left(-\frac{t}{\tau_{1}}\right)\right]
$$

where

$$
B=\left(\frac{1}{\chi_{\infty}}-\frac{1}{\chi_{0}}\right) \frac{1}{\ln \frac{\tau_{2}}{\tau_{1}}}=\frac{1}{\chi_{1}} \frac{1}{\ln \frac{\tau_{2}}{\tau_{1}}} .
$$

When $\tau_{1} \ll t_{B} \ll \tau_{2}$, it can be shown that

$$
\begin{aligned}
\frac{1}{\chi\left(t_{B}\right)} & =\frac{1}{\chi_{\infty}}+B\left(\gamma+\ln \frac{t_{B}}{\tau_{2}}\right) \\
& =A+B \ln t_{B}
\end{aligned}
$$

where $\gamma=0.5772 \ldots$ The time $t_{B}$ is taken from the reluctance versus $\log _{10} t$ curve in a linear region. $B \times 2.303$ is its slope and $B$ may be expressed as

$$
B=\frac{\frac{1}{\chi\left(t_{C}\right)}-\frac{1}{\chi\left(t_{D}\right)}}{2.303\left(\log _{10} t_{C}-\log _{10} t_{D}\right)}
$$

where $t_{C}$ and $t_{D}$ are two time values chosen to obtain the slope of the linear portion of the curve.
When $t>\tau_{1}$.

$$
\frac{1}{\chi(t)}=\frac{1}{\chi_{\infty}}+B E i\left(-\frac{t}{\tau_{2}}\right) .
$$

Hence the following expression is derived to obtain $\tau_{2}$ through successive approximations

$$
E i\left(-\frac{t}{\tau_{2}}\right)+\ln \tau_{2}=\frac{\frac{1}{\chi(t)}-\frac{1}{\chi\left(t_{B}\right)}}{B}+\gamma+\ln t_{B} .
$$

In the data of this paper $t=10^{4}$ seconds has been used in eq (9).

It can also be shown that for $\tau_{1}<<t_{B}<<\tau_{2}$

$$
\frac{1}{\chi\left(t_{B}\right)}=\frac{1}{\chi_{0}}+B\left(\gamma+\ln \frac{t_{B}}{\tau_{1}}\right)
$$

and at a time $t_{A}<<t_{B}$

$$
\frac{1}{\chi\left(t_{A}\right)}=\frac{1}{\chi_{0}}+B\left(\gamma+\ln \frac{t_{A}}{\tau_{1}}-E i\left(-\frac{t_{A}}{\tau_{1}}\right)\right) .
$$

From eqs (10) and (11), the following is derived to find $\tau_{1}$

$$
-E i\left(-\frac{t_{A}}{\tau_{1}}\right)=\frac{\frac{1}{\chi\left(t_{A}\right)}-\frac{1}{\chi\left(t_{B}\right)}+B \ln \frac{t_{B}}{t_{A}} .}{B} .
$$

The activation energy may be determined from Arrhenius' relationship

and

$$
\tau=\tau_{\infty} e^{E /{ } T}
$$

\begin{tabular}{|c|c|c|c|c|c|c|}
\hline Material & $\begin{array}{l}\text { Temper- } \\
\text { ature }\end{array}$ & $\tau_{1}$ & $\tau_{2}$ & $E_{1}$ & $E_{2}$ & $E_{0}$ \\
\hline 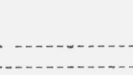 & $\begin{array}{c}{ }^{\circ} C \\
-10.0 \\
-13.0\end{array}$ & $\begin{array}{l}\text { sec } \\
76.6 \\
174\end{array}$ & $\begin{array}{c}s e c \\
4.8 \times 10^{4} \\
5.9 \times 10^{4}\end{array}$ & $\begin{array}{l}e V \\
0.66 \\
.85\end{array}$ & $\begin{array}{c}e V \\
0.97 \\
.75\end{array}$ & $\begin{array}{c}e V \\
0.82 \\
.80\end{array}$ \\
\hline
\end{tabular}

$$
\begin{gathered}
\tau_{1}=\tau_{\infty 1} e^{E_{1} / \kappa T} \\
\tau_{2}=\tau_{\infty_{2}} e^{E_{2} / \kappa T} .
\end{gathered}
$$

The activation energy equals the slope of the $\ln \tau$ versus $10^{3} / T\left({ }^{\circ} \mathrm{K}^{-1}\right)$ curve $\times \kappa$. See figure 13 and table 1.

Calculated data, $\left(1 / \chi^{\prime}\right)$ versus time, from eq (4) are compared to experimental data in figures 1 and 2 .

TABle 1. Materials $A$ and $B$

Activation energies and time constants at $100 \mathrm{kHz}$ computed by method described in section 5

The author thanks R. S. Yoshida for making many measurements, calculations and figures, for winding samples, and for making instrumentation 
improvements; J. L. Ivey for the arrangement of the Helmholtz coils and the demagnetizing equipment and for his helpful suggestions; R. D. Harrington for his astute observations and suggestions; M. B. Lindell for constructing instruments; J. L. Dalke for his encouragement; and H. C. Leistner and A. J. Pannone for preparing samples.

\section{References}

[1] Snoek, J. L., New developments in ferromagnetic materials, Elsevier Publ. Co., New York, N.Y., 2d ed., 139 pp. (1949).

[2] Marais, A., and Merceron, Th., Disaccommodation of the permeability of nickel-zine ferrites, C. R. Acad. Sci. 248, 2976-2978 (May 25, 1959) (In French).

[3] Marais, A., and Merceron, Th., Disaccommodation of the permeability of nickel-zinc ferrites, C. R. Acad. Sci. 249, 2511-2513 (Dec. 9, 1959) (In French).

[4] Krupička, S., and Vilim, F., Magnetic relaxation spectrum of ferrites $\mathrm{Mn}_{x} \mathrm{Fe}_{3-x} \mathrm{O}_{4+\gamma}$, Czech. J. Phys. B11. No. 1, 10-17 (1961).

[5] Krupička, S., A note on magnetic after-effect in iron rich ferrites, Czech. J. Phys. B11, No. 1, 457-459 (1961)

[6] Okada, T., and Yamadaya, T., Role of cation vacancies in disaccommodation of manganese ferrite, J. Phys. Soc. Japan 17, 1799 (1962).

[7] Krupička, S., Study of relaxation spectrum of $\mathrm{Mn}_{x} \mathrm{Fe}_{3-x}$ $\mathrm{O}_{4+\gamma}$ ferrites, J. Phys. Soc. Japan 17, Suppl. B-1, 304308 (1962)

[8] Braginski, A., Marais, A., and Merceron, Th., Magnetic after-effect in solid solutions of $\mathrm{Mn}$ and $\mathrm{Ni}$ ferrites with magnetite, J. Phys. Soc. Japan 17, Suppl. B-1, 300-303 (1962).

[9] Enz, U., Relations between disaccommodation and magnetic properties of manganese-ferrous ferrite, Physica XXIV, 609-624 (1958).

[10] Ohta, K., Time decrease of magnetic permeability in some mixed ferrites, J. Phys. Soc. Japan 16, No. 2, 250-258 (Feb. 1961).

[11] Krupička, S., Study of magnetic after-effect in magnesium manganese ferrite, Czech. J. Phys. 10, No. 11, 782-810 (1960)

[12] Iida, S., Mechanism of disaccommodation in ferrites, J. Phys. Soc. Japan 17, No. 1, 123-127 (Jan. 1962).

[13] Yanase, A., Mechanism of disaccommodation in ferrite, J. Phys. Soc. Japan 17, No. 6, 1005-1011 (June 1962).

[14] Ohta, K., and Yamadaya, T., Induced magnetic anisotropy and disaccommodation of manganese-zine ferrites, J. Phys. Soc. Japan 17, Suppl. B-1, 291-295 (1962).

[15] Braginski, M., and Merceron, Th., Influence of walls on after-effect phenomena, J. Phys. Radium 23, No. 10 , 876-877 (1962) (In French).

[16] Brissonneau, P., Magnetism-On the determination of the time constants of the magnetic after-effect from diffusion, Comp. Rend. Acad, Sci. 244, 1174-1177 (Feb. 25, 1957) (In French).
[17] Rathenau, G. W., and Fast, J. F., Initial permeabilities of sintered ferrites, Physica XXI, 964-970 (1955).

[18] Harrington, R. D., and Danielson, B. L., A technique for reducing errors in permeability measurements with coils, Proc. IRE 48, No. 3, 365-366 (March 1960).

[19] Brockman, F. W., Dowling, P. H., and Steneck, W. G., Dimensional effects resulting from a high dielectric constant found in a ferromagnetic ferrite, Phys. Rev. g\%, No. 1, 85-93 (1950)

[20] Krupicka, S., and Gerber, R., A contribution to studving the mechanism of permeability disaccommodation in ferrites, Czech. J. Phys. 10, No. 2, 158-160 (1960).

[21] Schnettler, F. J., and Gyorgy, E. M., Origin of the induced magnetic anisotropy in nickel ferrite, J. Appl. Phys. 35, No. 2, 330-334 (Feb. 1964).

[22] Gyorgy, E. M., and Schnettler, F. M., Induced anisotropy in YIG and Si and Mn additions, J. Appl. Phys, 35, No. 3, Part 2, 1067-1068 (March 1964).

[23] Pippin, J. E., and Hogan, C. L., Initial permeability spectra in ferrites and garnets, Scientific Report No. 1. Contract AF 19 (604)-1084, Gordon MeKay Laboratory, Harvard University, $39 \mathrm{pp}$. (April 1959).

[24] Rado, G. T., Wright, R. W., and Emerson, W. H., Ferromagnetism at very high frequencies III. Two mechanisms of dispersion in a ferrite, Phys. Rev. 80, No. 2, 273-280 (Oct. 1950).

[25] Rado, G. T., Magnetic spectra of ferrites, Rev. Mod. Phys. 25, No. 1, 81-89 (Jan. 1953).

[26] Rado, G. T., On the inertia of oscillating ferromagnetic domain walls, Phys. Rev. 83, No. 4, 821-826 (Aug. 1951).

[27] Kubota, B., Yanase, A., Taward, Y, and Neichi, Y., Induced anisotropy in iron rich nickel ferrite with a small cobalt substitution, J. Phys. Soc. Japan 1\%, Suppl. B-1, 296-299 (1962).

[28] Iida, S., and Inoue, T., Theoretical and experimental study of the induced anisotropy in iron cobalt ferrites and disaccommodation phenomena in ferrites, J. Phys. Soc. Japan 1\%, Suppl. B-1, 281-287 (1962).

[29] Ohta, K., Magnetocrystalline anisotropy and magnetic permeability of Mn-Zn-Fe ferrites, J. Phys. Soc. Japan 18, No. 5, 685-690 (May 1963).

[30] Brissonneau, P., Contribution a l'etude quantitative du traînage magnétique de diffusion du carbone dans le fer $\alpha$, J. Phys. Chem. Solids $\boldsymbol{7}, 22-51$ (Feb. 1958).

[31] Neel, M. L. Théorie Du traînage magnétique de diffusion, J. Phys. Radium 13, No. 5, 249-264, (Мay $1952)$.

[32] Richter, G., Über die magnetische Nachwirkung am carbony Leisen, Ann. Physik 29, 605-635 (1937).

[33] Becker, R., and Döring, W., Ferromagnetismus, Verlag von Julius Springer, Berlin (1939); Photo Lithoprint Reproduction, Edwards Brothers, Inc., Ann Arbor, Mich. (1943). 